\title{
The Influence of Heat Treatment on Homogeneity of Strength Properties and Structural Peculiarities of Low-Carbon Steel Fe-Mo-Nb-V-C Processed by High-Pressure Torsion
}

\author{
Elena G. Astafurova ${ }^{1,2, a)}$, Galina G. Maier, ${ }^{1, b)}$, Vera S. Koshovkina ${ }^{3}$, \\ Galina V. Chomyakova ${ }^{2}$, Marina S. Tukeeva ${ }^{1}$, Eugene V. Melnikov ${ }^{1}$, \\ Eugene V. Naydenkin ${ }^{1}$, Sergey V. Dobatkin ${ }^{4}$, and Pavel D. Odessky ${ }^{5}$ \\ ${ }^{1}$ Institute of Strength Physics and Materials Science SB RAS, Tomsk, 634055, Russia \\ ${ }^{2}$ National Research Tomsk State University, Tomsk, 634050, Russia \\ ${ }^{3}$ National Research Tomsk Polytechnic University, Tomsk, 634050, Russia \\ ${ }^{4}$ A.A. Baikov Institute of Metallurgy and Materials Science RAS, Moscow, 119991, Russia \\ ${ }^{5}$ Central Research Institute of Building Structures, Moscow, 109428, Russia \\ a) Corresponding author: astafe@ispms.tsc.ru \\ b) galinazg@yandex.ru
}

\begin{abstract}
A homogeneity of strength properties (microhardness) through the specimens and the peculiarities of an ultrafine-grained structure produced in low-carbon steel $\mathrm{Fe}-\mathrm{Mo}-\mathrm{Nb}-\mathrm{V}-\mathrm{C}$ by cold high-pressure torsion, depending on initial heat treatment of steel were studied. As a result of high-pressure torsion, the microhardness of steel was increased up to $700-770 \mathrm{HV}$ (in the middle part of disk radii), and the mean (sub)grain size was reduced to $\approx 100 \mathrm{~nm}$. Initial quenching of low-carbon steel provides a more homogeneous distribution of microhardness through the disk and the higher strength properties after high-pressure torsion in comparison with a normalizing initial state.
\end{abstract}

Keywords: high-pressure torsion, steel, ultrafine-grained structure, microhardness, transmission electron microscopy

\section{INTRODUCTION}

A study of ultrafine-grained structural states, fabricated by a severe plastic deformation, is the one of the rapidly developing areas of contemporary materials science. The creation of ultrafine-grained states opens the prospects for improving the baseline characteristics of metallic materials [1,2]. High-pressure torsion is a widely used technique for realization of extremely large strain while maintaining the integrity of the workpiece [1, 2]. One of the drawbacks of the method is the high degree of inhomogeneity of the structure and strength properties along the diameter of the disc after torsion, which is caused by the dependence of the strain on the distance to the center of the disc [2]. Such diversity can be avoided while increasing the strain and the applied pressure [2]. The other way to increase a structural homogeneity is initial treatment of specimens before high-pressure torsion. This work aims to establish the influence of the initial heat treatment of low-carbon steel $\mathrm{Fe}-\mathrm{Mo}-\mathrm{NbV}-\mathrm{C}$ on the features of structure and uniformity of the strength properties (microhardness) of the steel during deformation by cold high-pressure torsion.

\section{EXPERIMENTAL PROCEDURES}

The low-carbon steel used in this study had the chemical composition: $0.09 \mathrm{C}, 0.01 \mathrm{~N}, 0.007 \mathrm{P}, 0.32 \mathrm{Si}, 0.79 \mathrm{Cr}$, $0.16 \mathrm{Cu}, 0.032 \mathrm{Al}, 0.63 \mathrm{Mn}, 0.20 \mathrm{Ni}, 0.08 \mathrm{Mo}, 0.026 \mathrm{Ti}, 0.03 \mathrm{Nb}, 0.06 \mathrm{~V}$, balance Fe, wt.\%. The first part of specimens was quenched after $920^{\circ} \mathrm{C}$ for $0.5 \mathrm{~h}$ into the cold water, the second one was annealed (normalizing) at

International Conference on Physical Mesomechanics of Multilevel Systems 2014 AIP Conf. Proc. 1623, 19-22 (2014); doi: 10.1063/1.4898872

(C) 2014 AIP Publishing LLC 978-0-7354-1260-6/\$30.00 
$920^{\circ} \mathrm{C}$ for $0.5 \mathrm{~h}$ and cooled with a furnace. Electro-discharge machining was utilized to cut flat disks of $10 \mathrm{~mm}$ (diameter) $\times 0.45 \mathrm{~mm}$ (height) for high-pressure torsion. Mechanical grinding and a final electrochemical polishing (50 g of $\mathrm{CrO}_{3}$ in $200 \mathrm{ml}$ of $\mathrm{H}_{3} \mathrm{PO}_{4}$ ) were employed to remove all preparation-induced surface layers. The unconstrained high-pressure torsion [2] was conducted under a pressure of $P=6 \mathrm{GPa}$ for 5 revolutions at room temperature.

The microstructure of specimens after high-pressure torsion was investigated by a transmission electron microscope (TEM) (Tecnai 20 G2 TWIN) operating at an accelerating voltage of $200 \mathrm{kV}$. The average sizes of the (sub)grains were determined using dark-field TEM images [3]. The selected area electron diffraction patterns from an area of $0.95 \mu \mathrm{m}^{2}$ were evaluated to identify the different phases. X-ray diffraction studies were performed on a Shimadzu XRD 6000 X-ray diffractometer (with a monochromator) using $\mathrm{Cu}-\mathrm{K}_{\alpha}$ radiation. The scalar dislocation density was determined by X-ray diffraction, using the method described in [4]. The strength properties of the steel were analyzed using Duramin 5 microhardness tests (HV20).

\section{RESULTS AND DISCUSSION}

Before high-pressure torsion specimens had a structure of a lath ferrite with an average plate thickness of $0.4 \mu \mathrm{m}$ after quenching and ferritic-bainitic structure with a grain size of $10 \mu \mathrm{m}$ after normalizing annealing (the volume fraction of bainite was about 5\% according to optical and TEM images). Analysis of TEM-images and diffraction patterns revealed the spherical carbides in the initial state. X-ray analysis yielded an average dislocation density $(\rho)$ of $1.3 \times 10^{10} \mathrm{~cm}^{-2}$ and $\sim 10^{9} \mathrm{~cm}^{-2}$ prior to high-pressure torsion for quenched and normalized states respectively. The microhardness values and their distributions along the disks before and after high-pressure torsion are plotted in Fig. 1 for both initial states.

Quenching provided the initially higher microhardness values compared to normalized state. After high-pressure torsion the increase in microhardness up to 700-770 HV was observed compared to initial states (Fig. 1). The lowest values of microhardness were found in the centers of the disks subjected to high-pressure torsion. At the same time, these values were much higher in comparison with the values of microhardness in initial states. Consequently, the structure in central parts of the discs was also exposed to considerable deformation and refinement. The radial dependence of the microhardness is due to the inherent property of the high-pressure torsion, i.e., non-uniformity of the process [2]. Quenched specimens showed a higher hardening under high-pressure torsion and more homogeneous distribution of microhardness through the disk against initially normalized samples - the differences between central part of the disks and periphery were as high as $\approx 120 \mathrm{HV}$ for high-pressure torsion processed quenched state and $\approx 225 \mathrm{HV}$ for normalized one (Fig. 1).

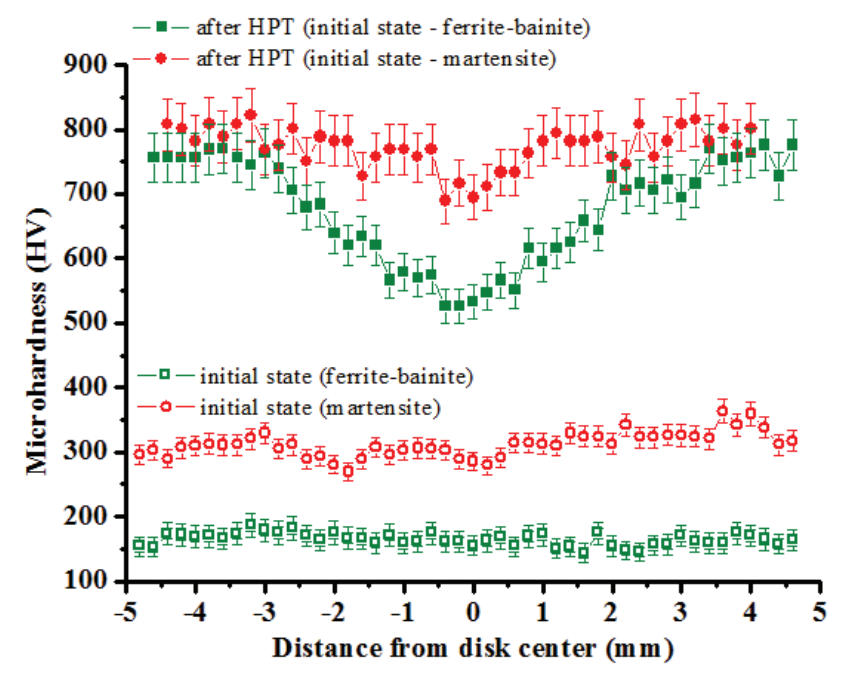

FIGURE 1. The Vickers microhardness (HV) versus the distance from the center of the disk for low-carbon steel in initial states and after high-pressure torsion 

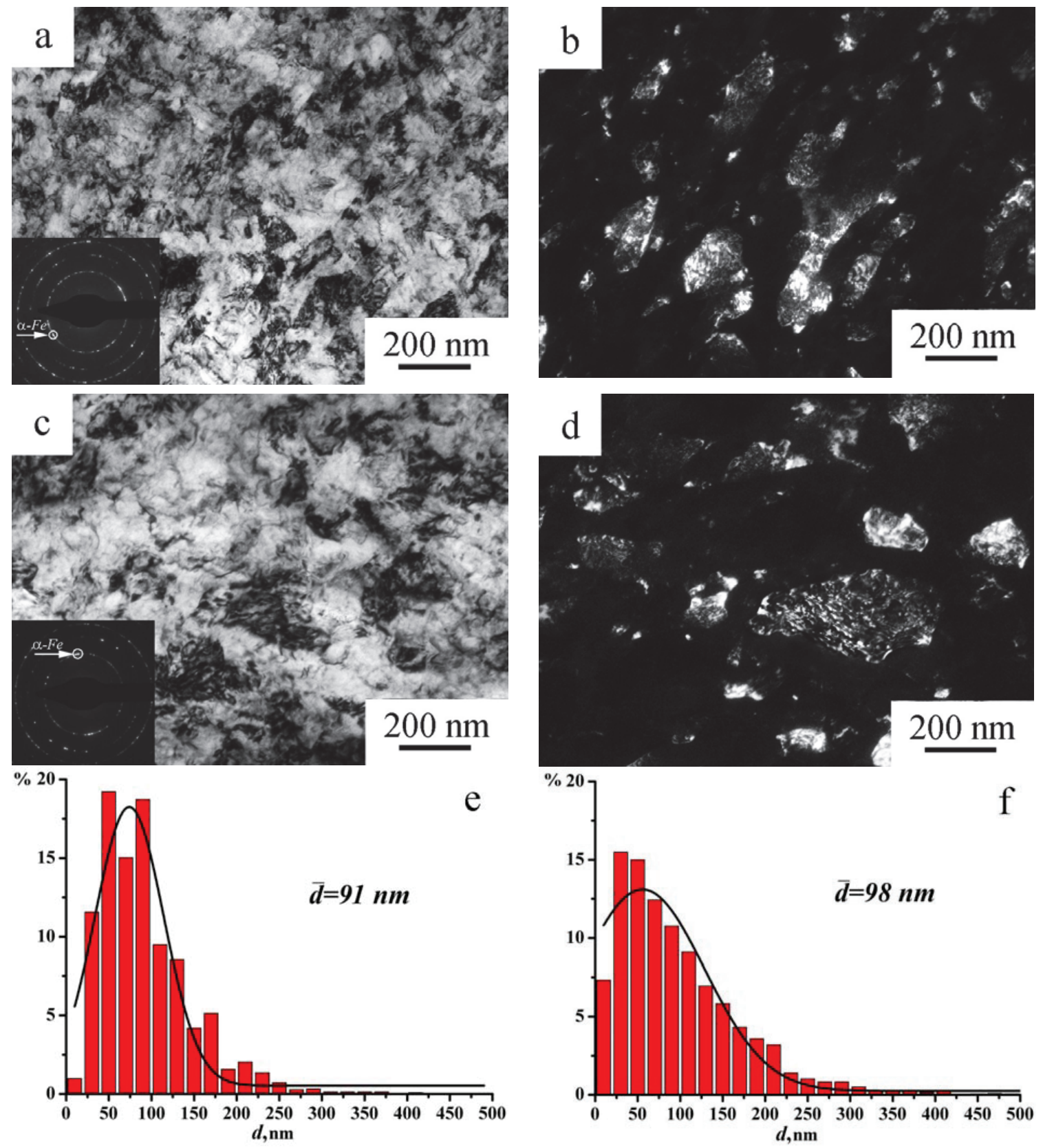

FIGURE 2. TEM micrographs (a-d) and subgrain size distribution (e-f) for low-carbon steel after high-pressure torsion at $20^{\circ} \mathrm{C}$ : bright-field images ( $a, c)$, dark-field images (b, d); initially normalized state (a, b, e), initially quenched state (c, d, f)

After high-pressure torsion steel specimens were highly deformed, and their structures were fragmented into small (sub)grains with the mean size of $91 \mathrm{~nm}$ (for initially normalized state) and $98 \mathrm{~nm}$ (for initially quenched state) as measured using TEM dark-field images (Fig. 2). After high-pressure torsion the subgrain size distributions are strongly dependent on initial state of steel: it is noticeably narrower for normalized and high-pressure torsion processed specimens compared to samples after quenching and high-pressure torsion. 
Despite the similar average values for the size of subgrains in states under investigation, the most probable grain size for high-pressure torsion processed initially quenched samples significantly lower $(55 \mathrm{~nm})$ than that for normalized specimens $(74 \mathrm{~nm})$. The extinction contours inside of grains are clearly visible in structures after highpressure torsion, the grain boundaries are distorted and diffused. The selected area electron diffraction patterns for high-pressure torsion processed samples are shaped close to a circle independently on initial state (Fig. 2(a, c)). The diffuse rings on the selected area electron diffraction patterns indicate the presence of nanoscale carbide phases which are homogeneously distributed in the ultrafine-grained ferritic matrix.

$\mathrm{X}$-ray analysis also identifies the differences between widths and intensities of lines for specimens in two different initial states subjected to high-pressure torsion. The sizes of a coherent-scattering region $\left(D_{h k l}\right)$ decrease down to 45 and $25 \mathrm{~nm}$ for high-pressure torsion processed quenched and normalized specimens. The values of a microstrain of a crystal lattice $(\Delta d / d)$ are changed from $\sim 10^{-4}$ (initial state) to $\sim 3.5 \times 10^{-3}$ under high-pressure torsion independently on initial treatment which indicates the presence of the large internal microstresses $\sigma^{\mathrm{II}}$ of $740 \mathrm{MPa}$ after high-pressure torsion. The values of dislocation density, calculated from the broadening of X-ray lines, are of $\sim 10^{11} \mathrm{~cm}^{-2}$ after high-pressure torsion which are much higher than that for the initial states.

Thus, the formation of a dispersed structure in quenching of steel samples contributes to a more fragmented (and as a consequence, more strengthened) structure under high-pressure torsion compared with normalizing state. Another advantage of quenching against normalizing prior to high-pressure torsion for steel samples is more uniform distribution of the microhardness on the disks after torsion.

\section{SUMMARY}

High-pressure torsion of low-carbon steel $\mathrm{Fe}-\mathrm{Mo}-\mathrm{Nb}-\mathrm{V}-\mathrm{C}$ provides a refinement of its structure down to $<100 \mathrm{~nm}$ which depends on initial heat treatment of the specimens. As a result of high-pressure torsion, the microhardness of steel was increased up to 700 and $770 \mathrm{HV}$ (in the middle part of disk radius) for initially normalized and quenched states respectively. Initial quenching of low-carbon steel provides a more homogeneous distribution of microhardness through the disk and the higher strength properties after high-pressure torsion in comparison with normalizing initial state.

\section{ACKNOWLEDGMENTS}

This research was partially supported by the Fundamental Research Program of RAS on 2013-2016 (III.23.2.2) and a grant of President of Russian Federation (project No. SP-4682.2013.1). The authors wish to thank Prof. V. Bataev, Prof. A. Bataev, and A. Smirnov for their assistance with transmission electron microscopy.

\section{REFERENCES}

1. R. Z. Valiev, R. K. Islamgaliev, and I. V. Alexandrov, Prog. Mater. Sci. 45, 103 (2000).

2. A. P. Zhilyaev and T. G. Langdon, Prog. Mat. Sci. 53, 893 (2008).

3. D. B. Williams and C. B. Carter, Transmission Electron Microscopy (Springer, USA, 1996).

4. G. K. Williamson and R. E. Smallman, Phil. Mag. 1, 34 (1956).

5. M. V. Degtyarev, L. M. Voronova, and T. I. Chashchukhina, The Phys. Met. Metall. 99(4), 411 (2005). 